\title{
COMPARATIVE OF PARAMETERS IN THE Forging PROCESS BY DIFFERENT APPLICATION LOAD
}

\author{
Marin, M.; Garcia, E.; Nunez, P. \& CAMACHO, A.
}

Abstract: In this study is determined behaviour to the workpiece under conditions of load similar which take place in compression forming processes (Kopp, et al., 2001). The workpieces are tested in an open die forging process. The forging process is carried out through two manners of the application load. First the forming load is applied continuous manner and then, it is made the incremental manner. The alloy AA 6082-T6 is employed. The geometry of the workpiece is being changed along the analysis

In this work the stress - strain curves are obtained. These are analysed under the influence of the forming load. The roughness achieved in the contact surface is studied. Results shown that the values stress - strain are lower when the forming load is applied incremental manner and that the average roughness is lower in incremental forming load process. Therefore the effect of friction is minimized.

Key words: open die forging, stress- strain, friction, roughness
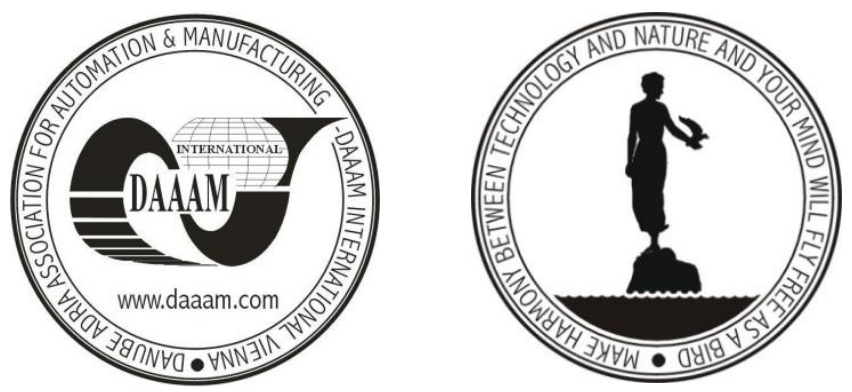

Authors' data: Ass. Prof. Marin, M[arta]*; Asoc. Prof. Garcia, M[anuel] M[ale]**; Nunez, P.*; Dr. Ing. Assoc. Prof. Camacho, A[na] M[aria]*, National Distance University of Spain, Juan del Rosal, 12, 28040 Madrid, Spain, ** Department of Manufacturing Engineering UNED University Juan del Rosal 12, 28040 Madrid Spain,mmarin@ind.uned.es, villaobispo@gmail.com, amcamacho@ind.uned.es

This Publication has to be referred as: Marin, M[arta]; Nunez, P., Camacho, A[na] M[aria] \& Garcia, M[anuel] M[ale] (2013), Comparative of Parameters in the Forging Process by Different Application Load, Chapter 24 in DAAAM International Scientific Book 2013, pp. 449-458, B. Katalinic \& Z. Tekic (Eds.), Published by DAAAM International, ISBN 978-3-901509-94-0, ISSN 1726-9687, Vienna, Austria DOI: $10.2507 /$ daaam.scibook.2013.24 
Marin, M.; Garcia, E.; Nunez, P. \& Camacho, A.: Comparative of Parameters in the...

\section{Introduction}

In this work, the behaviour to the workpiece has been determined under conditions of load similar which take place in compression forming processes. In this study, the alloy AA 6082-T6 (UNS A96082) has been employed. This alloy is used in the forming processes under conditions of plastic deformation such as forging (Bariani, et al., 2004). The workpieces have been subjected to open a die forging process. The study has been carried out through two different manners of applied the load. In first case, the load has been applied the continuous manner until a value of specific load. In the other test, the workpiece has been formed by means of incremental loads until to reach a value in particular.

In the analyses, stress - strain and roughness in the contact surface are obtained. In previous carried studies (Altan, et al., 2005) have been shown that stress - strain curve of a material depends on the friction between the contact surfaces, the strain rate and temperature of the test (Fereshteh-Saniee, et al., 2004; Forcellese, et al., 1994; Wang \& Ramaekers, 1996). This last parameter is considered when the test is carried out at high temperatures where the material has a different behaviour in the ranges of phase change. In this work, all tests have been carried to room temperature. Also, it has been shown that when the test is performed the test to room temperature, the strain rate almost no influences (Altan, et al., 1983).

The tests have been carried out to room temperature hence temperature and strain rate no influence in the process. In the analysis, the plate speed of the testing machine has been remained to $2,5 \mathrm{~mm} / \mathrm{min}$ for all the tests carried. Therefore, under these conditions in the performed tests, the most influential parameter is the friction. To reduce the effect of friction on the test has been applied the Bulge Correction Factor Method (BCFM) (Fereshteh-Saniee \& Fatehi-Sichani, 2006). In all cases, a graphite-based lubricant has been used between the contact surfaces.

The roughness in contact surface between the top surface of the workpiece and plate of testing machine is other considered parameter. The reached roughness in the process the open die forging has been measured. The workpieces have different geometries where the diameter is remained constant and its height has been changing (Marín, 2011).

Finally, the obtained results have been compared considering the different manners of to apply the load in the open die forging process.

\section{Methodology}

In this study, some tests are carried out in open die forging process. To achieve the tests are chosen a test compression universal machine, model HD-D as it is shown in the figure 1a. The workpieces are submitted to an uniaxial compression load. This load is caused by two plane plates on opposite sides, as it is seen in the figure $1 \mathrm{~b}$. 


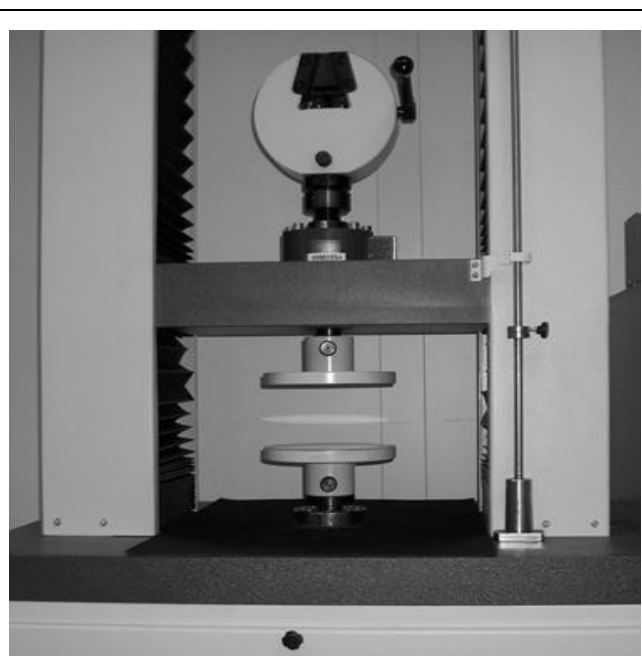

a)

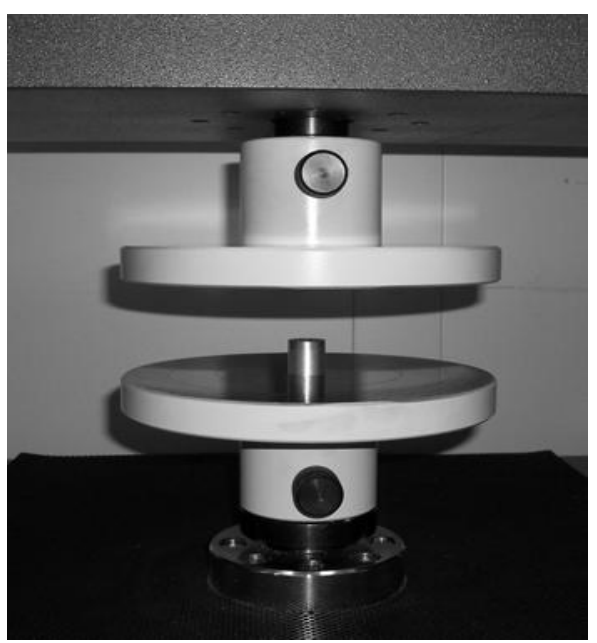

b)

Fig. 1. Experimental equipment: a) machine overview; b) detail of the compression plates

During the carrying out of the forging processes, the contact surfaces of the workpiece are covered with lubricant. The used lubricant is graphite. In all carried out tests, such in continuous compression as in incremental compression, the test finishes when the compression load achieves the value of the $90 \mathrm{kN}$.

The forces and the changes in height of the workpiece are gotten throughout the tests. The stress -strain curves are obtained after to carry out an analytical process with values of the forces and heights.

One of the parameters than the most influence in a forging process is the friction. When the compression load is applied, the workpiece begins to deform. Once above the elastic behavior of the material, the workpiece is deformed uniformly. In this portion of the deformation, when the height is reduced, the area increases uniformly along the same. In this case, the stress and strain are calculated directly.

Compression process advances and at some point, the workpiece is not uniformly deformed appearing the geometry of the barreled specimen. This is caused by friction between the contact surfaces. The friction does not allow the contact surfaces slide freely causing the curvature in the free surfaces (Kopp \& Wiegels, 1999; Altan, et al., 1983). In this moment is not so easy to calculate the stress and strains. To solve this problem, it is used a correction factor of the curve (FereshtehSaniee \& Fatehi-Sichani, 2006).

\subsection{Bulge Correction Factor Method}

This method is based on the geometry of the barreled specimen that occurs during testing (Fereshteh-Saniee \& Fatehi-Sichani, 2006). In this method, a conversion factor is calculated. This factor is applied to the axial stress produced in the median plane of the specimen (barreled curve). This correction factor only depends on the geometry of the specimen. 
Marin, M.; Garcia, E.; Nunez, P. \& Camacho, A.: Comparative of Parameters in the...

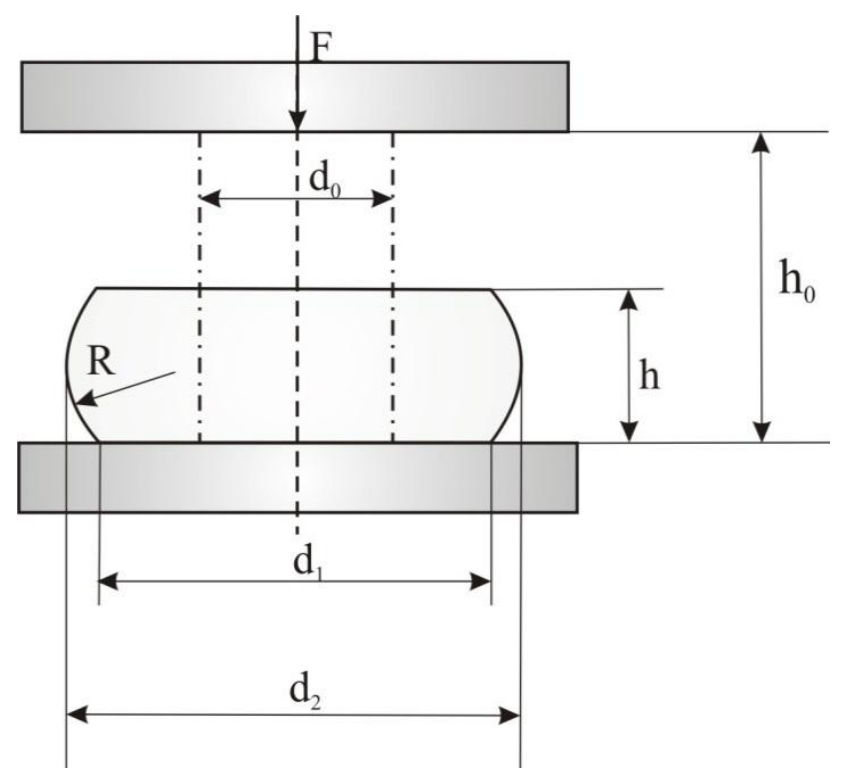

Fig. 2. Geometry of the specimen before and after carrying out the uniaxial compression test

In figure 2 shows the geometry of the specimen before and after of the test. In the figure are seen the geometric parameters of each state. To determine stress on each instant is applied a correction factor called Bulge Correction Factor, $C$, to the average stress achieved in the axial mid-plane of the specimen deformed. This factor is applied the average axial stress at mid-plane of the deformed specimen, $\sigma_{m}$, as shown in equation 1.

$$
\sigma_{\mathrm{m}}=\frac{\mathrm{F}}{\pi \cdot \mathrm{a}^{2}}
$$

where $F$ is the instant forming load and $a$ is the radius at the mid-plane of the deformed specimen $\left(d_{2} / 2\right.$ in Fig. 2).

The relationship for the bulge correction factor is derived using an analytical procedure and based on the analysis of stress distribution at the mid-plane of the deformed sample (Ettouney \& Hardt, 1983; Mielnik, 1991):

$$
C=\left[\left(1-\frac{2 \cdot R}{a}\right) \cdot \ln \left(1-\frac{a}{2 \cdot R}\right)\right]^{-1}
$$

where $R$ is the radius barreled curve. The radius $R$ is calculated through radius of curvature known (Horton, et al., 1959) to reach the following empirical formula

$$
\mathrm{R}=\frac{\mathrm{h}^{2}+\left(\mathrm{d}_{2}-\mathrm{d}_{1}\right)^{2}}{4 \cdot\left(\mathrm{d}_{2}-\mathrm{d}_{1}\right)}
$$


where $d_{l}$ is the diameter of the contact surface. This equation relates the smaller diameter and the greater diameter with final height.

Finally, the corrected flow stress is obtained applying this bulge correction factor, $C$, to the average axial stress at mid-plane of the deformed specimen, $\sigma_{m}$ :

$$
\sigma=\mathrm{C} \cdot \sigma_{\mathrm{m}}
$$

Its corresponding true compression strain $(\varepsilon)$ can also be determined as follow:

$$
\varepsilon=\ln \left(\frac{\mathrm{h}_{0}}{\mathrm{~h}}\right)
$$

To apply the bulge correction factor, in the test must be applied with the incremental forming load.

\subsection{Material}

The employed material has been the aluminium alloy AA 6082-T6 [UNS A96082] whose main alloying elements are magnesium and silicon. This kind of alloy has been chosen by its versatility and its high employ in manufacturing processes (Duckham \& Knutsen, 1998). This alloy has an high toughness.

\subsection{Geometry of the workpiece}

The studied workpieces have different geometries. During of the study, the diameters remain constant while the heights have being changed. In this sense, the initial geometry of the studied workpieces have the following initial dimensions, diameter $10 \mathrm{~mm}$ and height of $5 \mathrm{~mm}$ and $10 \mathrm{~mm}$, with these geometries of the workpiece are obtained a specific shape factor.

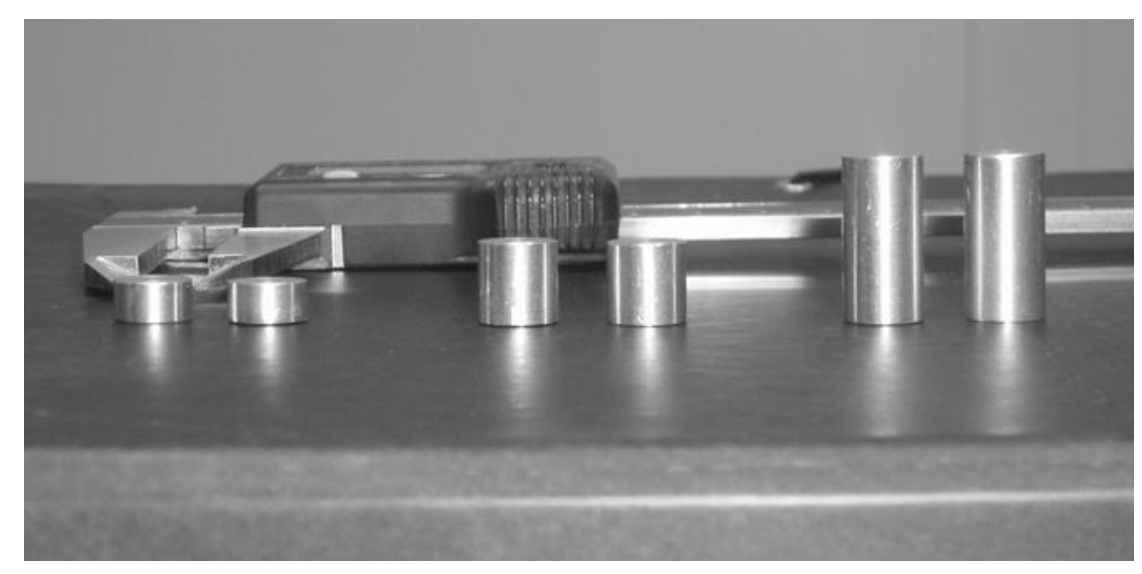

Fig. 3. Initial geometry of the workpieces

The shape factor is defined as the relationship between the initial height and initial diameter of the workpiece (Marín, 2011). In this work, it have been studied the shape factors $(h / d): 0,5$ and 1 . In the figure 3 is shown the initial geometry of the 
Marin, M.; Garcia, E.; Nunez, P. \& Camacho, A.: Comparative of Parameters in the...

workpieces. Everyone the geometries of the workpiece were tested by two methods, continuous compression test and incremental compression test.

\subsection{Roughness}

Previous to start the tests, the roughness in the top surface of the workpieces were measured. When the open die forging process finished, the roughness are measured again in the same surface. The roughness is measured along the diameter of the surface. This operation is achieved in all tests.

\section{Results}

The stress - strain have been obtained in the test for different geometries of the workpiece, and the results are shown in figure 4. In the figure it is represented the curves for the two methods of load application, continuous and incremental, in the workpieces with different geometries.

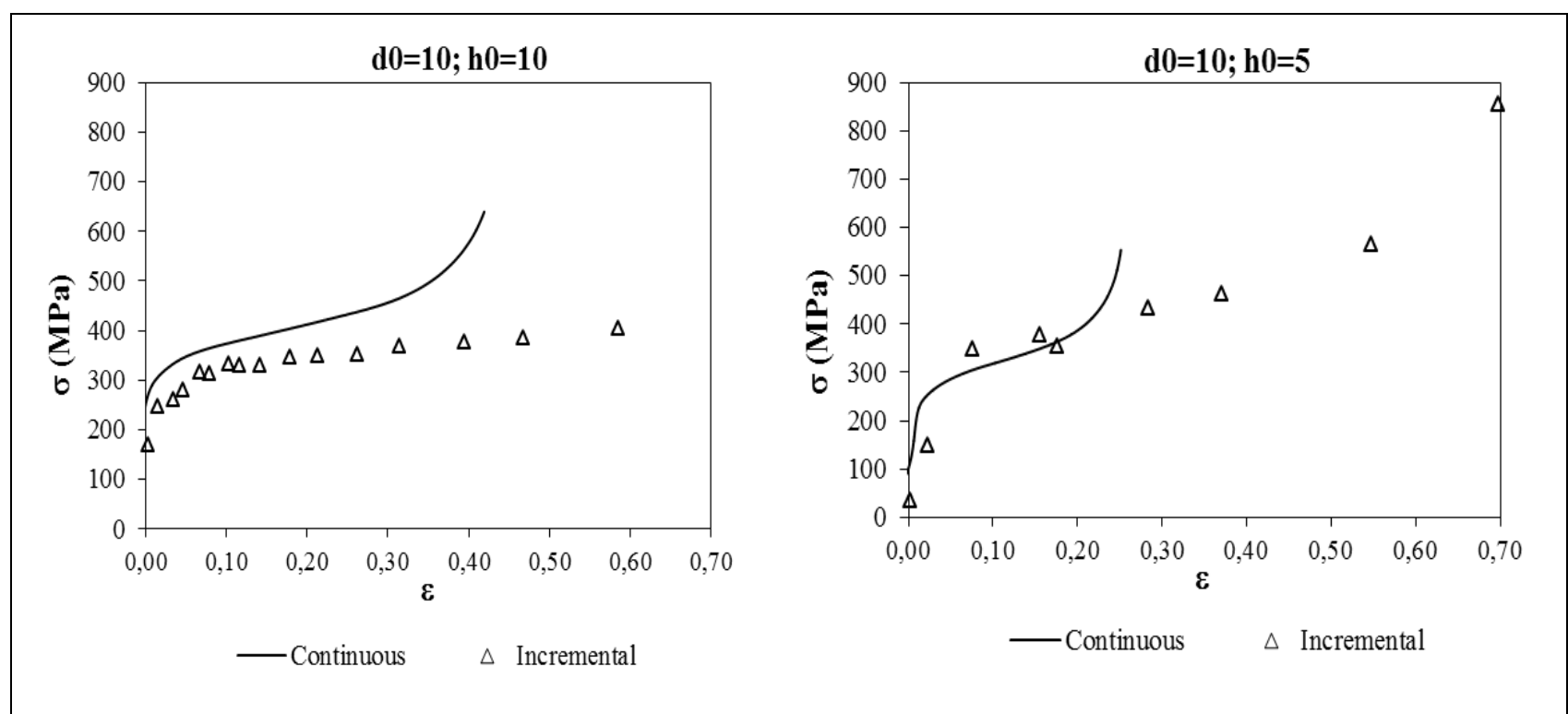

Fig. 4. Stress - strain curves obtained in forging process for different geometries of the workpiece

In the figure 4 is observed that the stress - strain curve with bulge factor correction is below on the curve obtained in continuous uniaxial compression test. The highest deformations in the workpieces are obtained during the application of the incremental forming load. This is due to each increase in the contact surfaces are lubricated, reducing the friction.

In tables 1 and 2 are shown the geometric dimensions of the tested workpieces. There is a greater height reduction in the incremental forming load process, it is obtained a lower final height. The difference between the diameter at the mid-plane and at the contact surface of the piece is less in the pieces carried out with incremental forming load. Then barreled curve is smaller in the incremental forming load process due to that the friction is lower. 


\begin{tabular}{|l|c|c|}
\hline \multirow{2}{*}{$\mathbf{h}$} & \multicolumn{2}{|c|}{ Workpieces $\mathbf{( m m )}$} \\
\cline { 2 - 3 } & $\mathbf{h}_{\mathbf{0}}=\mathbf{5}$ & $\mathbf{h}_{\mathbf{0}}=\mathbf{1 0}$ \\
\hline $\mathbf{d}_{\mathbf{1}}$ & 2,53 & 4,22 \\
\hline $\mathbf{d}_{\mathbf{2}}$ & 14,20 & 15,28 \\
\hline$\frac{\mathbf{d} \mathbf{2}-\mathbf{d} \mathbf{1}}{\mathbf{2}}$ & 14,38 & 15,72 \\
\hline
\end{tabular}

Tab. 1. Finished measurements of the workpieces made in the incremental forming load

\begin{tabular}{|c|c|c|}
\hline \multirow{2}{*}{$\mathbf{h}$} & \multicolumn{2}{|c|}{ Workpieces (mm) } \\
\cline { 2 - 3 } & $\mathbf{h}_{\mathbf{0}}=\mathbf{5}$ & $\mathbf{h}_{\mathbf{0}}=\mathbf{1 0}$ \\
\hline $\mathbf{d}_{\mathbf{1}}$ & 2,81 & 4,54 \\
\hline $\mathbf{d}_{\mathbf{2}}$ & 12,93 & 14,20 \\
\hline$\frac{\mathbf{d} 2-\mathbf{d} \mathbf{1}}{\mathbf{2}}$ & 13,68 & 15,42 \\
\hline
\end{tabular}

Tab. 2. Finished measurements of the workpieces made in the continuous forming load

During the performance of incremental forming load, it has been observed that the barreled curve is begun to form in the nearest area to the top surface of the workpiece. This happens because friction is not the same on both surfaces, there is an increased friction on the top surface (Im, et al., 2006).

In the figure 5 is shown the roughness profile on the contact surface of the initial workpiece. The roughness has been measured along the diameter of the contact surface.

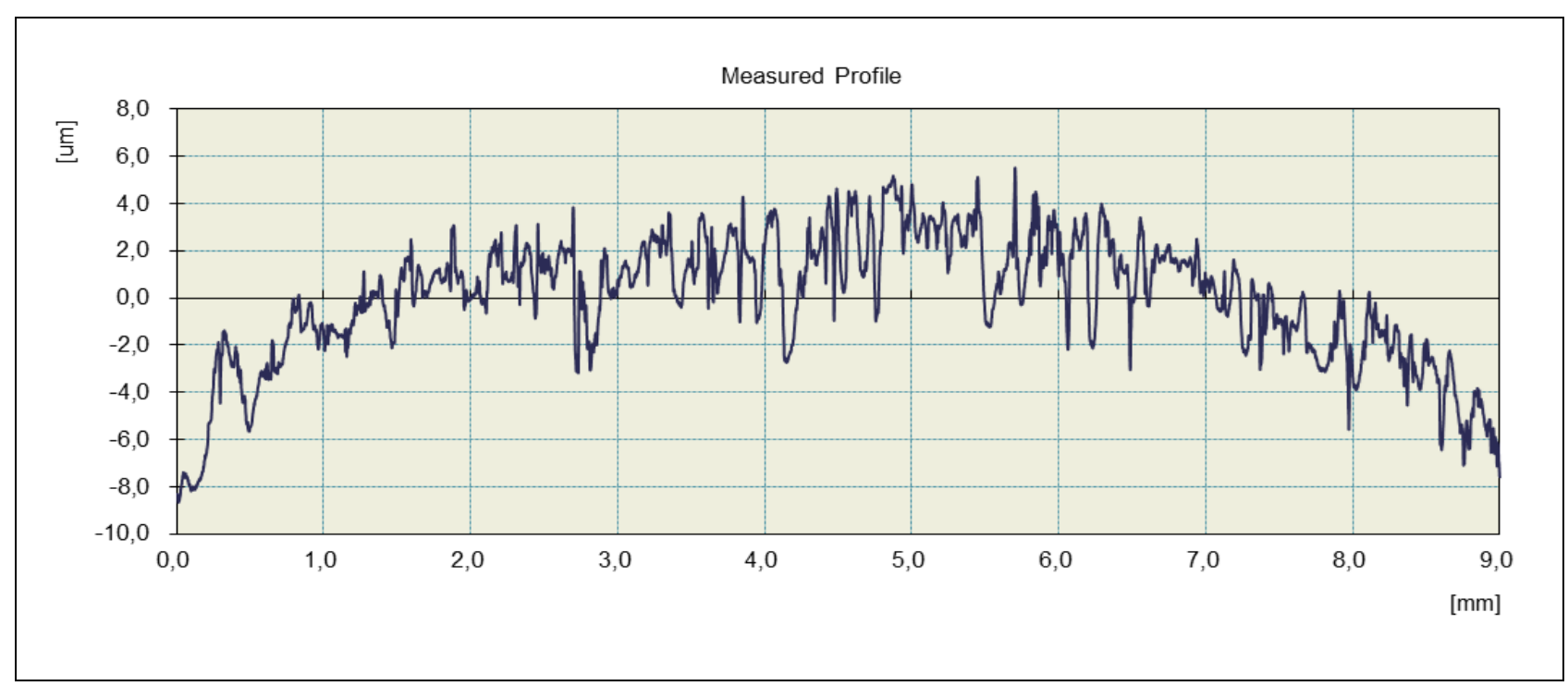

Fig. 5. Roughness profile in initial workpiece 
Marin, M.; Garcia, E.; Nunez, P. \& Camacho, A.: Comparative of Parameters in the...

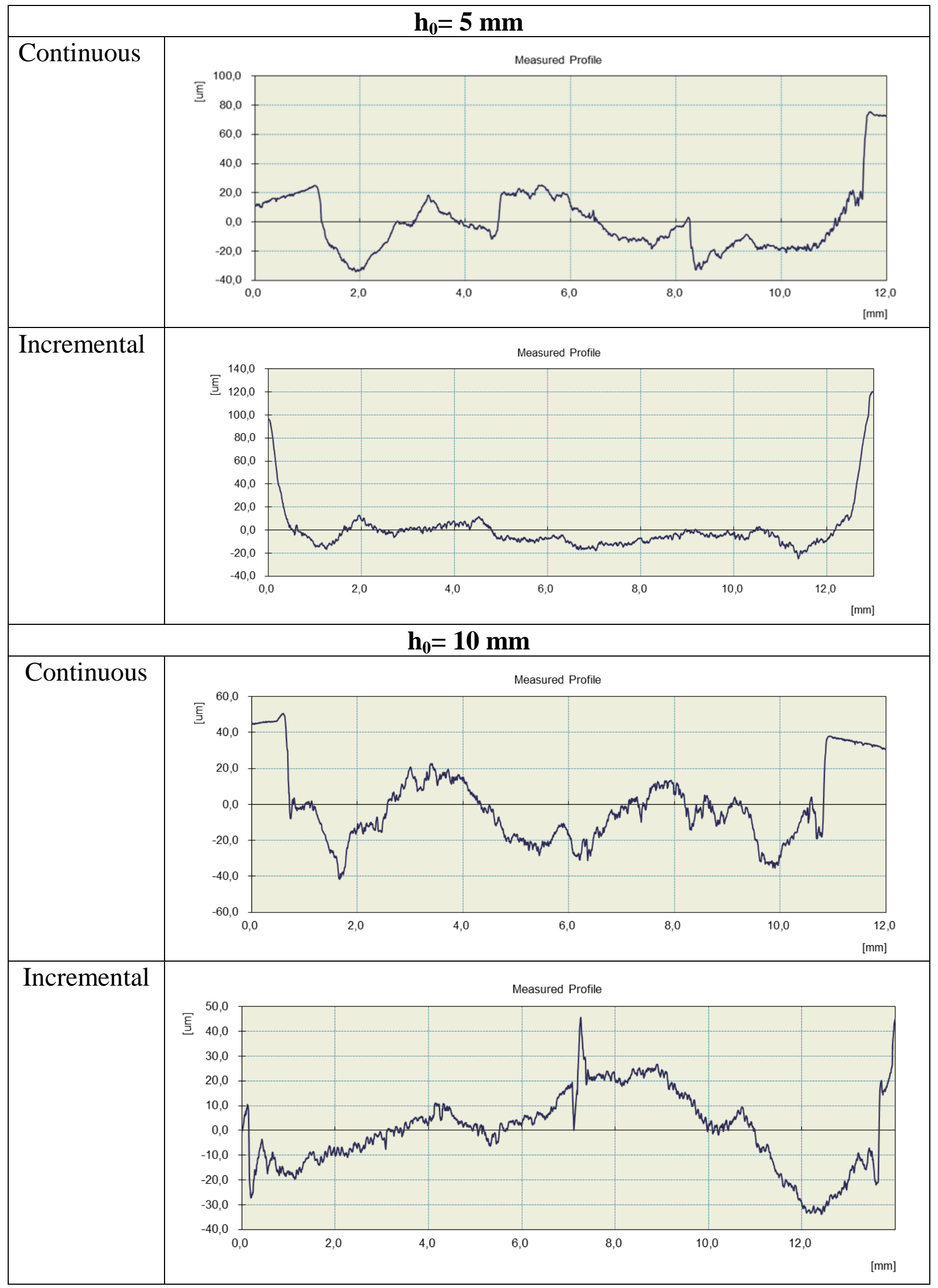

Fig. 6. Roughness profiles in workpieces with height $5 \mathrm{~mm}$ and $10 \mathrm{~mm}$ for the incremental forming load and continuous forming load 
In the figure 6 are shown the obtained roughness profiles in different test. They are represented the roughness profiles for different geometries workpieces in forging process. The roughness profiles are obtained with incremental forming load and continuous forming load.

The average roughness values have been obtained in the contact surface. In the table 2 is seen the values for different geometries of the workpiece in forging process with incremental forming load and continuous forming load. When the geometry workpiece no changes, it is observed that the average roughness is higher if the forming load is continuous. In the continuous forming load process, it is observed that the higher the height, the higher the average roughness. While in the incremental forming load, it is seen that the higher the height, the lower the average roughness.

\begin{tabular}{|l|c|c|}
\hline \multirow{2}{*}{} & \multicolumn{2}{|c|}{ Ra $(\mu \mathrm{m})$} \\
\cline { 2 - 3 } & $\mathbf{h}_{\mathbf{0}}=\mathbf{5 m m}$ & $\mathbf{h}_{\mathbf{0}}=\mathbf{1 0 m m}$ \\
\hline continuous forming load & 5,8 & 6,14 \\
\hline incremental forming load & 4,87 & 3,02 \\
\hline
\end{tabular}

Tab. 3. Finished measurements of the workpieces made in the incremental forming load

\section{Conclusion}

In this work has carried out a comparative some parameters such the strain stress and roughness in compression forming process. For this purpose, a workpiece has been formed through an open die forging. In this process, the load has been applied two manners. First the forming load has been applied continuous manner. Later the same process has been repeated but in this case, the forming load has been incremental manner.

It has been shown that the stress - strain are lower when the forming load is applied incremental manner. The other hand, it has been test that the average roughness is lower in incremental forming load process. Even it is shown that the higher the height, the lower the average roughness.

Therefore if it is applied an incremental forming load it is achieved a higher stress and a lower roughness. This minimizes the effect of friction allowing decrease the required energy of the compression process and the tool wear.

In future works these tests will be compared with other compression process such as the indentation process. It will be taken into account the surface roughness and different geometries of the workpiece should be considered.

\section{Acknowledgements}

The authors gratefully acknowledge the Ministry of Science and Innovation of Spain for funding this work via Project DPI2009-07300. 
Marin, M.; Garcia, E.; Nunez, P. \& Camacho, A.: Comparative of Parameters in the...

\section{References}

Altan, T., Ngaile, G. \& Shen, G., 2005. Cold and hot forging fundamentals and applications. Columbus(Ohio): ASM international, Materials Park

Altan, T., Oh, S. \& Gegel, H., 1983. Metal forming fundamentals and applications. Columbus(Ohio): ASM International, Materials Park

Bariani, P., Dal Negro, T. \& Bruschi, S., 2004. Testing and modelling of material response to deformation in bulk metal forming. CIRP Annals - Manufacturing Technology, 53(2), pp. 573-595

Duckham, A. \& Knutsen, R., 1998. Asymmetric flow during plane strain compression testing of aluminum alloys. Materials Science and Engineering A, Volume 256, pp. 220-226

Ettouney, O. \& Hardt, D., 1983. A method for in process failure prediction in cold upset forging. Journal of Engineering for Industry, Volume 105, pp. 161-167

Fereshteh-Saniee, F. \& Fatehi-Sichani, F., 2006. An investigation on determination of flow curves at room temperature and under forming conditions. Journal of Materials Processing Technology, Volume 177, pp. 478-482

Fereshteh-Saniee, F., Pillinger, I. \& Hartley, P., 2004. Friction modeling for the physical simulation of the bulk metal forming processes. Journal of Materials Processing Technology, Volume 153-154, pp. 151-156

Forcellese, A., Gabrielli, F., Barcellona, A. \& Micari, F., 1994. Evaluation of friction in cold metal forming. Journal of Materials Processing Technology, Volume 45, pp. 619-624

Horton, H., Ryffel, H. \& Schubert, P., 1959. Machinery's handbook. 16a ed. New York: Industrial Press

Im, Y., Kang, S. \& Cheon, J., 2006. A novel technique of friction and material property measurement by tip test in cold forging. Journal of Engineering Manufacture, 220(1), pp. 81-9.

Kopp, R. et al., 2001. Flow stress measuring by use of cylindrical compression test and special application to metal forming processes. Steel Research, 72(10), pp. 394401

Kopp, R. \& Wiegels, H., 1999. Einführung in die Umformtechnick. Aachen(Germany): Institut für Bildsame Formgebung

Marín, M., 2011. Estudio de factores tecnológicos en procesos de compresión por deformación plástica de materiales metálicos dúctiles por el método de los elementos finitos. España: Tesis Doctoral

Mielnik, E., 1991. Metalworking science and engineering. s.l.:McGraw-Hill

Wang, S. \& Ramaekers, J., 1996. Measurement of friction and material flow-stress by a plane-strain compression tribometer. Journal of Materials Processing Technology, Volume 57, pp. 345-350

Watts, A. \& Ford, H., 1952. An experimental investigation of the yielding of strip between smooth dies. Proceedings of the Institution of Mechanical Engineers, part B1, pp. 448-553 